\title{
Life history of fjord cod from the Skagerrak in the mid-2000s compared to 1905
}

\author{
Marthe Bråthen Lund ${ }^{1}$, Esben Moland Olsen ${ }^{1,2}$, Sigurd Heiberg Espeland ${ }^{2}$, \\ Nils Chr. Stenseth ${ }^{1,2, *}$ \\ ${ }^{1}$ Centre for Ecological and Evolutionary Synthesis, Department of Biology, University of Oslo, PO Box 1066 Blindern, \\ 0316 Oslo, Norway \\ ${ }^{2}$ Institute of Marine Research, Flødevigen Marine Research Station, 4817 His, Norway
}

\begin{abstract}
Life history changes serve as stress indicators in harvested populations. Data from recent decades show that many species of marine fish are now maturing at younger ages and smaller sizes, associated with a general increase in harvest intensity. However, data from earlier times are generally sparse or lacking. In this study we compare present life history characteristics of fjord cod Gadus morhua in the Skagerrak, southern Norway, to century-old (1905) scientific data. Contrary to our expectations, age and length distributions were shifted towards older and larger fish in the most recent data set compared to the historic sample. Also, fish in the historic sample tended to be smaller at age and reached $50 \%$ maturity at a smaller size and younger age compared to the present sample. These results are in contrast to most other studies on life history changes in harvested fish.
\end{abstract}

KEY WORDS: Age-structure $\cdot$ Atlantic $\operatorname{cod} \cdot$ Fjord $\cdot$ Harvesting $\cdot$ Life history $\cdot$ Size-structure Resale or republication not permitted without written consent of the publisher

\section{INTRODUCTION}

Worldwide, commercially exploited fish stocks have declined substantially over the last decades (Hutchings et al. 2010), often with associated changes in life history characteristics. Most notably, spawning populations tend to be increasingly dominated by young individuals (Trippel 1995). This may be due to demographic effects such as age-truncation (Beamish et al. 2006, Stenseth \& Rouyer 2008), phenotypic plasticity in growth responses to environmental change (Hendry et al. 2008), or harvest-induced evolutionary changes (Law 2000, Olsen et al. 2004). Whatever the underlying mechanism, changes in age and size at maturation may serve as early-warning 'stress indicators' in harvested populations (Trippel 1995).

Our current understanding of phenotypic changes in harvested populations relies, to a large extent, on timeseries data collected during recent decades, while data from earlier times are generally lacking (but see Jackson et al. 2001, Limburg et al. 2008). This is unfortunate, since marine fish such as the Atlantic cod Gadus morhua have been harvested for centuries (Hutchings \& Myers 1995). In the present study, we have been able to elucidate longer-term phenotypic changes in a coastal ecosystem by comparing Atlantic cod life history data from a scientific study conducted more than a century ago (Dahl \& Dannevig 1906) to the present.

\section{MATERIALS AND METHODS}

In November 1905, 925 Atlantic cod were sampled during an early scientific investigation in the Søndeled fjord, a small fjord in southern Norway, in collaboration with local fishermen setting cod traps in shallow, coastal water. Body length was measured for all fish, while age and maturity state (immature versus maturing) was determined for 138 individuals collected on November 25, 1905. These life history data are available as full tables of individual characteristics in the original publication (Dahl \& Dannevig 1906). During November 2006, we re-sampled this study area (Fig. 1), also in collaboration with a local fisherman. 


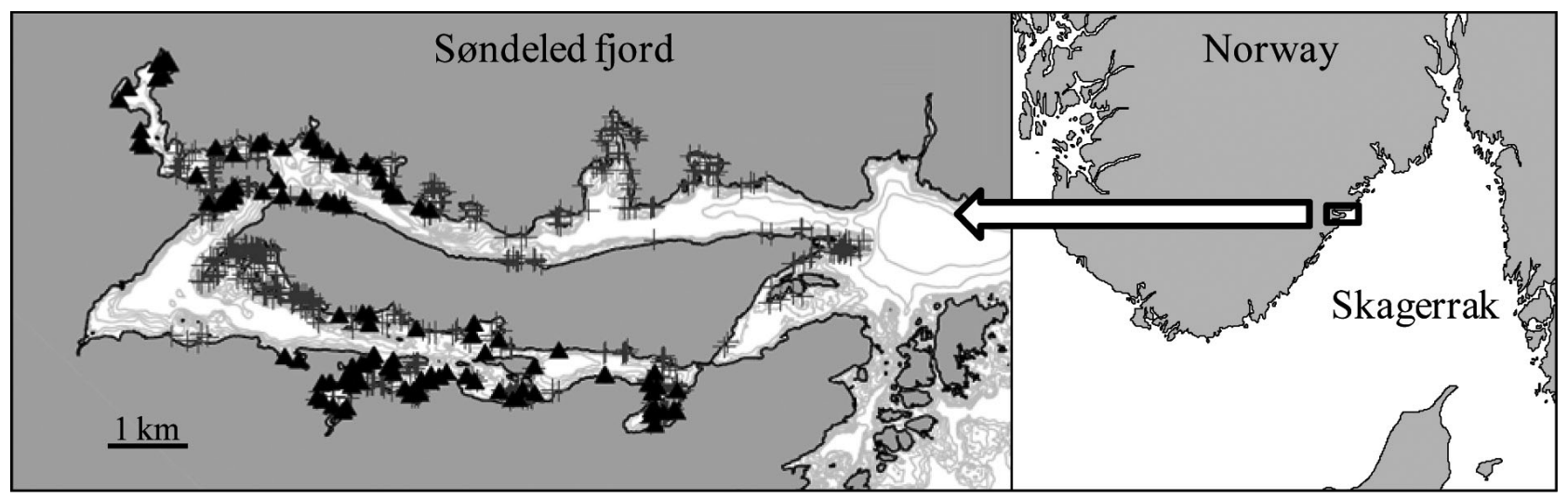

Fig. 1. Study area. Søndeled fjord $\left(58.73^{\circ} \mathrm{N} 9.17^{\circ} \mathrm{E}\right)$, the Skagerrak, showing cod trap positions during November 2006 (black triangles) and from May to June 2005-2007 (grey crosses)

We collected 502 cod in shallow water (1 to $5 \mathrm{~m}$ depth) using traditional traps for harvesting cod (and other species such as eel). These traps are set on the bottom and are not baited, but instead have a leading net which will guide the fish through a narrow opening and into the trap. Historical photographs, and a historical trap stored at the Institute of Marine Research Flødevigen, Norway, indicate that this basic design has not changed significantly over time. The diameter of the inner opening where the fish have to pass in order to enter the trap is very similar $(15 \mathrm{~cm})$, indicating that selectivity is roughly the same. This inner opening is designed as a slit which the cod can find its way through, but will not be able to find its way back out again. The available historical trap is made of rope and thread from natural fibres and has wooden rings. The modern traps are made of synthetic fibres and have metal rings.

We measured the fork length of each fish to the nearest $\mathrm{cm}$. Maturity state was determined from visual inspection of the gonads: (1) Immature. Gonads are small, eggs or milt not visible to the naked eye. (2) Maturing. Gonads are developing, visible eggs or milt. This binary classification was sufficient for comparison with the historical sample, where Dahl \& Dannevig (1906) describe that they classified the fish as immature or maturing based on visual inspection of the gonads. The exact criteria for maturity classification are not provided for the 1905 data, but the authors state that they adopted a conservative strategy if in doubt (i.e. classifying borderline cases as juvenile fish). Age was determined from otoliths (Bagenal \& Tesch 1978), both in the historical sample and in the contemporary sample. Fish were sampled prior to the spawning season, which is generally from February to April in coastal Skagerrak (Espeland et al. 2007). Therefore, one year $(y)$ was added to the age of each fish, so that age refers to age at spawning (spring in $y_{i+1}$ ) compared to age at sampling (autumn in $y_{i}$ ).
The study area was also sampled just after the spawning season during 3 consecutive years, from May to June 2005-2007 (Fig. 1; 2005: $\mathrm{n}=581,2006: \mathrm{n}=$ 880, 2007: $\mathrm{n}=473$ ). The spring samples were collected in the same way as the autumn sample in 2006, in collaboration with the same fisherman and using his traps. However, during spring sampling the cod were not killed but instead tagged and released. The capture-recapture information in these data will be reported elsewhere, but the size distributions are presented here to show recent intra- and inter-annual variability in the size distribution of the cod population in this fjord.

Statistical analyses were performed using program $\mathrm{R}$ (version 2.10.1; R Development Core Team 2009). Length and age distributions in 1905 versus 2006 were compared using a Kolmogorov-Smirnov test. Furthermore, the 90th percentile length (the length that $90 \%$ of the fish are less than) was used as a measure of the large-fish component in the population. Similarly, the 90th percentile age was used as a measure of the oldfish component. Length $(L)$ at age $(A)$ in year $(y) 1905$ versus 2006 was compared using a linear model:

$$
\log (L)=\beta_{0}+\beta_{1} A+\beta_{2, y}
$$

where $\beta_{0}$ is the intercept. The probability of being mature $(p)$ as a function of body length $(L)$ or age $(A)$ in year (y) 1905 versus 2006 was compared using logistic regression models:

$$
\begin{aligned}
& \operatorname{logit}(p)=\beta_{0}+\beta_{1, Y}+\beta_{2} L+\beta_{3, Y} L \\
& \operatorname{logit}(p)=\beta_{0}+\beta_{1, Y}+\beta_{2} A+\beta_{3, Y} A
\end{aligned}
$$

Parameter estimates from these models were used to estimate the age and length at which the fish reached $50 \%$ maturity $\left(A_{50}\right.$ and $\left.L_{50}\right)$. This historical comparison was performed without sex as a covariate, since no information about sex was available from the 1905 
sample. However, male cod typically tend to mature at a smaller size and younger age compared to female cod (e.g. Olsen et al. 2005). Therefore, if the sex ratio differs between the historical sample and the recent sample, the historical comparison might be biased. In order to test the robustness of our result to such a bias, we analysed the effect of sex $(s)$ on the length $(L)$ and age $(A)$ based maturity of cod from the 2006 sample:

$$
\begin{aligned}
& \operatorname{logit}(p)=\beta_{0}+\beta_{1, s}+\beta_{2} L+\beta_{3, s} L \\
& \operatorname{logit}(p)=\beta_{0}+\beta_{1, s}+\beta_{2} A+\beta_{3, s} A
\end{aligned}
$$

We then compared the 1905 result to each of the sexspecific maturity patterns from the 2006 sample. Note that we have estimated the probability of being mature at a particular age or length. Such maturity ogives differ conceptually from probabilistic maturation reaction norms that estimate the age- and size-specific probabilities of maturing (i.e. first-time spawning). Maturation reaction norms provide more direct information about the actual maturation event (Heino et al. 2002) compared to maturity ogives, which do not separate first-time spawners and repeat spawners. However, the maturation reaction norm approach requires a fairly large sample size in order to provide reliable estimates of maturation (Olsen et al. 2005), and could not be applied to our samples from coastal Skagerrak. Note, however, that our data on maturity at 2 yr of age will provide direct information on the maturation event, because this is the youngest age at which any maturing fish are found (i.e. the age group does not contain any repeat spawners).

\section{RESULTS}

The body lengths of cod sampled from the Søndeled fjord in autumn 1905 ranged from 20 to $58 \mathrm{~cm}$, while the body lengths of cod sampled in autumn 2006 ranged from 9 to $68 \mathrm{~cm}$ (Fig. 2). The length distribution in 1905 was shifted significantly towards smaller fish compared to the 2006 sample $(\mathrm{p}<0.001)$. The mean length in 1905 was $31 \mathrm{~cm}$ compared to $41 \mathrm{~cm}$ in 2006. The 90th percentile length was $37 \mathrm{~cm}$ in 1905 compared to $52 \mathrm{~cm}$ in 2006. Cod sampled during spring 2005-2007 revealed some recent variation in length distributions. The mean length of cod sampled during spring 2005, 2006, and 2007 was 40, 31, and $42 \mathrm{~cm}$, respectively. The 90th percentile lengths for these 3 spring samples were close to the 2006 autumn sample, i.e. 52,48 , and $53 \mathrm{~cm}$, respectively. The age of the cod sampled in autumn 1905 ranged from 2 to $6 \mathrm{yr}$, while the age of cod sampled in autumn 2006 ranged from 1 to 9 yr (Fig. 3). The age distribution (spawning season age) was shifted significantly towards younger
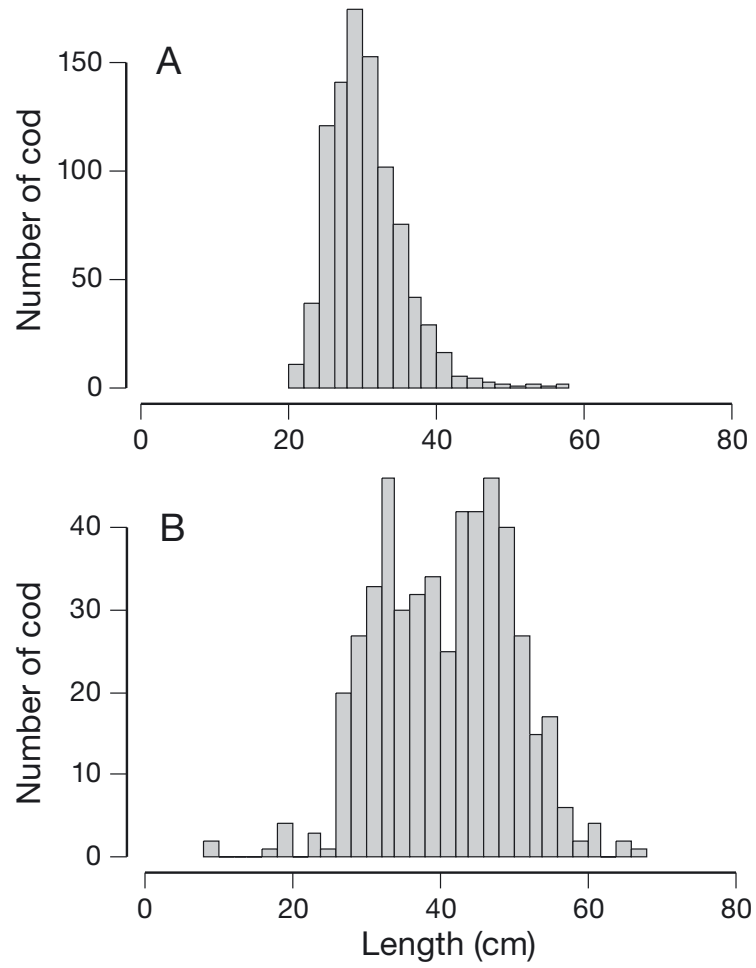

Fig. 2. Gadus morhua. Length distribution of cod from the Søndeled fjord in the Skagerrak in (A) November 1905 and (B) November 2006
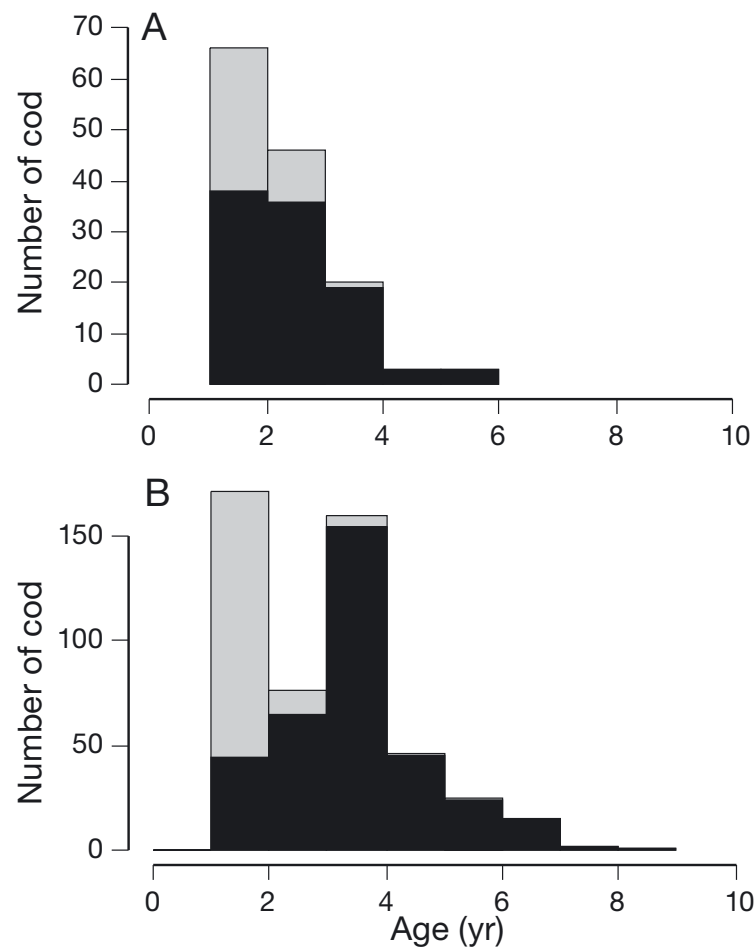

Fig. 3. Gadus morhua. Age distribution of juvenile (grey bars) and maturing (black bars) cod from the Søndeled fjord in the Skagerrak in (A) November 1905 (B) and November 2006. Males and females are pooled 
fish in 1905 compared to 2006 ( $p<0.001)$, despite the fact that young fish belonging to the 2005 year class were very abundant in the 2006 sample. The 90th percentile age was $4 \mathrm{yr}$ in 1905 and $5 \mathrm{yr}$ in 2006. Also, the cod was significantly larger at age in 2006 compared to 1905 (Fig. 4).

In both 1905 and 2006 some cod matured at an age of 2 yr (Fig. 3). The proportion of mature 2-yr-old fish was 0.57 in 1905, compared to 0.26 in 2006. Both age- and length-based maturity ogives differed significantly between 1905 and 2006 (Table 1). In the length-based maturity ogive, the year-length interaction effect was only marginally significant (Table 1). In a simplified

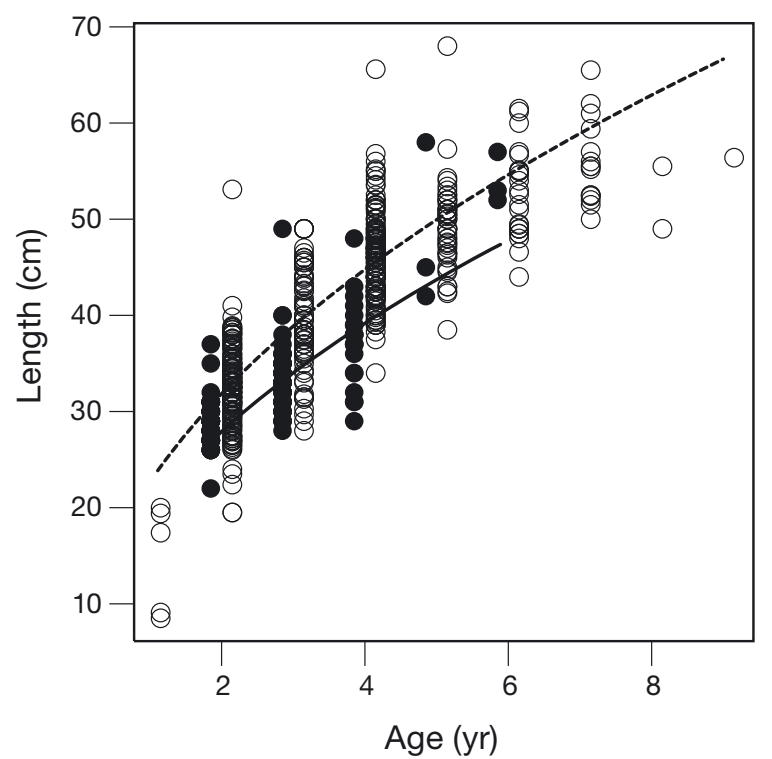

Fig. 4. Gadus morhua. Length-at-age of Skagerrak coastal cod sampled in November 1905 (๑, solid line) and November 2006 (O, dashed line) as predicted from a linear model (see 'Materials and methods'; $\beta_{1}=0.49, \mathrm{SE}=0.01, \mathrm{p}<0.0001$ and $\left.\beta_{2}=0.13, \mathrm{SE}=0.01, \mathrm{p}<0.0001\right)$

Table 1. Parameter estimates, with standard error (SE), of logistic regression models describing length $(L)$ and age $(A)$ based maturity ogives of Skagerrak coastal cod sampled in year $(y)$ 1905 and 2006 (see 'Materials and methods'). The year 1905 was coded as 0 in the models

\begin{tabular}{|ccccr|}
\hline Model no. & $\begin{array}{c}\text { Model term } \\
\text { estimate }\end{array}$ & Parameter & SE & $\mathrm{p}$ \\
\hline$(2)$ & Intercept & -4.24 & 1.68 & 0.012 \\
& $Y_{2006}$ & -5.30 & 1.91 & 0.006 \\
& $L$ & 0.17 & 0.06 & 0.003 \\
& $y_{2006} L$ & 0.11 & 0.06 & 0.076 \\
& & & & \\
(3) & Intercept & -2.05 & 0.82 & 0.012 \\
& $y_{2006}$ & -3.11 & 0.96 & 0.001 \\
& $A$ & 1.16 & 0.33 & $<0.001$ \\
& $y_{2006} A$ & 0.96 & 0.38 & 0.012 \\
& & & & \\
\hline
\end{tabular}

model containing only additive effects of year and length, both the year effect and the length effect were highly significant $(\mathrm{p}<0.001)$. In 1905 , cod reached $A_{50}$ at $1.77 \mathrm{yr}(\mathrm{SE}=0.25)$ and $L_{50}$ at $25.7 \mathrm{~cm}(\mathrm{SE}=2.0)$, while in 2006, cod reached $A_{50}$ at $2.44 \mathrm{yr}(\mathrm{SE}=0.06)$ and $L_{50}$ at $35.0 \mathrm{~cm}(\mathrm{SE}=0.50)$. In the 2005 sample, both age- and length-based maturity ogives differed between the sexes (sex-age interaction effect, $\mathrm{p}=$ 0.005 ; sex-length interaction effect, $\mathrm{p}=0.005)$. Female $\operatorname{cod}(\mathrm{n}=256)$ reached $A_{50}$ at $2.54 \mathrm{yr}(\mathrm{SE}=0.08)$ and $L_{50}$ at $36.4 \mathrm{~cm}(\mathrm{SE}=0.6)$, while male cod $(\mathrm{n}=244)$ reached $A_{50}$ at $2.26 \mathrm{yr}(\mathrm{SE}=0.12)$ and $L_{50}$ at $33.09 \mathrm{~cm}(\mathrm{SE}=$ $0.97)$.

\section{DISCUSSION}

The present study provides a window into the past life history of a marine fish, the Atlantic cod Gadus morhua. In contrast to earlier studies on harvested populations (e.g. Trippel 1995, Engelhard \& Heino 2004, Olsen et al. 2004), the available data suggest that the fjord cod populations in the Skagerrak were more dominated by young, small spawners a century ago compared to the present.

It is not straight-forward to conclude the underlying causes of such a historical change. In general, both demography (mortality), phenotypic plasticity (growth responses), and evolution could play a role (Trippel 1995, Law 2000, Stenseth \& Rouyer 2008). The sparseness of large and old fish in the historical sample certainly indicates that mortality was high during this period, unless habitat use and migration patterns have also changed so that older and larger fish have become more available for capture in recent years. Historical tagging data are available back to the early 1900s, and these data provide some support for a change in mortality regime. The highest tag return rates were observed during the first half of the 20th century (Espeland et al. 2008), indicating that fishing pressure was particularly high in this period. We note that the tagging data are not strongly conclusive since the earliest study (1905) also had fairly low tag return rates. This might, however, be related to a higher tag mortality rate and tag loss rate compared to later studies. The earliest study used a metal plate attached to the operculum, and reports of damaged fish were numerous (Dahl \& Dannevig 1906). Overall, the tagging data do not suggest that there has been a change in the habitat use or migration patterns of the Skagerrak coastal cod during the last century (Espeland et al. 2008).

The observational nature of our data and the somewhat limited information about historical changes in mortality do not allow us to infer whether plasticity or evolution has been the main driver of the observed 
phenotypic change in maturation. However, the observed change in growth may be helpful for understanding the change in maturation. The data presented here suggest that cod growth (size-at-age) is now faster than what was the case in the early 1900s. Considering the knowledge that faster growing fish generally tend to speed up their life history (Alm 1959), the present combination of faster growth and delayed maturation is not what one would expect to see as a purely plastic effect, but indicates that evolution may also have been involved.

We recognise that using a century-old dataset will add uncertainty to the results, for several reasons: (1) It is not known whether total length or fork length was measured in the historical sample. Because we measured fork length in our recent sample, the historical fish might be biased upwards (if total length was measured). Mean length, length-at-age, and length-at$50 \%$ maturity were smaller in the historical sample, meaning that our historical comparison could be somewhat conservative if the historical sample was based on total length. (2) The methodology of age determination from hard parts such as otoliths and scales was in its infancy during the early 1900s, and hence this historical information might be less precise than the age determination performed in the recent sample. (3) The historical estimates of maturity could be biased if the sex ratio in the sample was skewed. This information was not available to us. However, both male and female maturity ogives in the recent sample were shifted towards relatively old and large fish compared to the pooled historical sample. This suggests that our historical comparison was fairly robust against any bias caused by skewed sex ratios. (4) The exact design of the fishing gear has changed, although historical photos and some preserved historical gear indicate that the basic construction has been kept (see 'Materials and methods'). This gear is designed to be set in shallow (about 1 to $5 \mathrm{~m}$ ) depth, and so bottom depth should be comparable among the samples. In any case, recent telemetry data have shown that cod in the Skagerrak region display a marked diurnal vertical migration pattern, visiting the most shallow $(<5 \mathrm{~m})$ near-shore habitats during nighttime and retreating to deeper habitats during the day (Espeland et al. 2010). This pattern is visible for both juvenile cod and larger mature cod. Hence, both large and small cod tend to show up in trap-catches (Lekve et al. 2006). (5) We do not know the exact location of the historical traps, but we do know that they were all from the Søndeled fjord. Recent population genetic analyses have shown that local populations of Skagerrak coastal cod can be found on a fjord scale, with no significant genetic differentiation within fjords (Jorde et al. 2007). Hence, all our samples are likely from the same coastal popula- tion. (6) It is not clear how the characteristics of the population may have varied on a year-to-year basis throughout the 20th century, and we only have one year of data from the early 1900s. Still, the 3 spring samples (2005-2007) clearly supported the result from the autumn 2006 sample, showing that this measure of the size-distribution was fairly robust. In particular, the large-fish components (90th percentiles) were similar for all samples collected during the mid-2000s, while the 1905 sample was more dominated by small fish.

In conclusion, the present study shows that not all populations of harvested fish appear to follow the same general trend towards age-truncation and maturation at younger ages and smaller sizes. Given that life history changes serve as stress indicators in harvested populations (Trippel 1995), our data showing delayed maturation of fjord cod in the early 21st century compared to the early 20th century suggest that these populations now experience somewhat relaxed pressure. Still, compared to many other cod stocks (Trippel 1995, Olsen et al. 2005), Skagerrak coastal cod mature at a relatively younger age and smaller size. We note that coastal fish such as the fjord cod are easily accessible for people using small boats and simple gear and have been harvested since the Stone Age (Limburg et al. 2008). There are signs of overharvesting of cod in some coastal waters already during the 19th century (Hutchings \& Myers 1995), meaning that harvest-induced life history changes may have occurred even before our historical data from 1905.

Acknowledgements. This study was funded by the Norwegian Research Council through the Oceans and the Coast programme. We thank J. A. Knutsen and H. Knutsen for help with data collection. Four anonymous referees provided very useful feedback on an earlier version of this contribution.

\section{LITERATURE CITED}

Alm G (1959) Connection between maturity, size and age in fishes. Inst Freshw Res Drottningholm Rep 40:5-145

Bagenal T, Tesch FW (1978) Age and growth. In: Bagenal TB (ed) Methods for assessment of fish production in fresh waters. Blackwell, Oxford, p 112-114

Beamish RJ, McFarlane GA, Benson A (2006) Longevity overfishing. Prog Oceanogr 68:289-302

Dahl K, Dannevig GM (1906) Studies on the effectiveness of releasing cod larvae for stock improvement in fjords in eastern Norway. Aarsberetn Norg Fisk 1:1-121 (in Norwegian)

Engelhard GH, Heino M (2004) Maturity changes in Norwegian spring-spawning herring Clupea harengus: compensatory or evolutionary responses? Mar Ecol Prog Ser 272: $245-256$

> Espeland SH, Gundersen AF, Olsen EM, Knutsen H, Gjøsæter J, Stenseth NC (2007) Home range and elevated egg densities within an inshore spawning ground of coastal cod. ICES J Mar Sci 64:920-928 
Espeland SH, Olsen EM, Knutsen H, Gjøsæter J, Danielssen DS, Stenseth NC (2008) New perspective on fish movement: kernel and GAM smoothers applied to a century of tagging data on coastal cod. Mar Ecol Prog Ser 372:231-241

Espeland SH, Thoresen AG, Olsen EM, Stige LC, Knutsen H, Gjøsæter J, Stenseth NC (2010) Diel vertical migration patterns in juvenile cod from the Skagerrak coast. Mar Ecol Prog Ser 405:29-37

Heino M, Dieckmann U, Godø OR (2002) Measuring probabilistic reaction norms for age and size at maturation. Evolution 56:669-678

Hendry AP, Farrugia TJ, Kinnison MT (2008) Human influences on rates of phenotypic change in wild animal populations. Mol Ecol 17:20-29

Hutchings JA, Myers RA (1995) The biological collapse of Atlantic cod off Newfoundland and Labrador: an exploration of historical changes in exploitation, harvesting technology, and management. In: Arnason R, Felt L (eds) The North Atlantic fisheries: successes, failures and challenges. Institute of Island Studies, Charlottetown, p 37-93

Hutchings JA, Minto C, Ricard D, Baum JK, Jensen OP (2010) Trends in the abundance of marine fishes. Can J Fish Aquat Sci 67:1205-1210

Jackson JBC, Kirby MX, Berger WH, Bjorndal KA and others (2001) Historical overfishing and the recent collapse of coastal ecosystems. Science 293:629-637

Jorde PE, Knutsen H, Espeland SH, Stenseth NC (2007)

Editorial responsibility: Stylianos Somarakis,

Heraklion, Greece
Spatial scale of genetic structuring in coastal cod Gadus morhua and geographic extent of local populations. Mar Ecol Prog Ser 343:229-237

> Law R (2000) Fishing, selection, and phenotypic evolution. ICES J Mar Sci 57:659-668

- Lekve K, Enersen K, Enersen SE, Gjøsæter J, Stenseth NC (2006) Interannual variability in abundance and length of young coastal cod in the subtidal zone. J Fish Biol 68: $734-746$

Limburg KE, Walther Y, Hong B, Olson C, Storå J (2008) Prehistoric versus modern Baltic Sea cod fisheries: selectivity across the millennia. Proc Biol Sci 275:2659-2665

> Olsen EM, Heino M, Lilly GR, Morgan MJ, Brattey J, Ernande B, Dieckmann U (2004) Maturation trends indicative of rapid evolution preceded the collapse of northern cod. Nature 428:932-935

Olsen EM, Lilly GR, Heino M, Morgan MJ, Brattey J, Dieckmann U (2005) Assessing changes in age and size at maturation in collapsing populations of Atlantic cod (Gadus morhua). Can J Fish Aquat Sci 62:811-823

R Development Core Team (2009) R: a language and environment for statistical computing. R Foundation for Statistical Computing, Vienna

Stenseth NC, Rouyer T (2008) Destabilized fish stocks. Nature 452:825-826

Trippel EA (1995) Age at maturity as a stress indicator in fisheries. BioScience 45:759-771

Submitted: December 23, 2009; Accepted: December 1, 2010 Proofs received from author(s): February 4, 2011 